\title{
Review: antidepressant drugs are effective in dysthymia
}

Lima MS, MoncrieffJ. A comparison of drugs versus placebo for the treatment of dysthymia: a systematic review. (Cochrane Review, latest version 5 Jan 98). In: the Cochrane Library. Oxford: Update Software.

\section{Question}

In patients with dysthymia are antidepressant drugs effective?

\section{Data sources}

Studies were identified by electronic searches of The Cochrane Library, EMBASE/Excerpta Medica, Medline, PsycLIT, Biological Abstracts, and LILACS; reference searching; reviewing conference abstracts and book chapters on the treatment of depression; contacting pharmaceutical companies for unpublished trials; and by personal communication.

\section{Study selection}

Studies were selected if they were randomised controlled trials that focused on the use of drugs compared with placebo in patients with dysthymia. Studies were excluded if the analysis of major depression and dysthymia was mixed, or if depression was secondary to another disorder.

\section{Data extraction}

Data were extracted on patient characteristics, type of therapy, changes in dysthymia, relapse rate, and adverse events.

\section{Main results}

15 trials involving 1964 patients were included. Similar results were obtained for the efficacy of the different drug groups considered: tricyclic antidepressants (TCAs); monoamine oxidase inhibitors (MAOIs); selective serotonin reuptake inhibitors (SSRIs); and other drugs (sulpiride, amineptine, and ritanserin). A treatment response occurred more often and more patients had full remission in the TCA, SSRI, and MAOI groups when compared with the placebo groups (table). Patients in the TCA group had more adverse effects than those in the placebo group (table). This difference did not occur for SSRIs or MAOIs when compared with placebo.

\section{Conclusion}

Antidepressant drugs are effective in the treatment of dysthymia with no differences between class of drugs other than more adverse effects with tricyclic antidepressants.

Antidepressant drugs v placebo in patients with dysthymia*

\begin{tabular}{|c|c|c|c|c|}
\hline \multirow[b]{2}{*}{ Outcomes } & \multicolumn{2}{|c|}{ Weighted event rates } & \multirow[b]{2}{*}{$R B I(95 \% C I)$} & \multirow[b]{2}{*}{$N N T(C I)$} \\
\hline & $T C A$ & Placebo & & \\
\hline Treatment response & $56 \%$ & $32 \%$ & $75 \%$ (45 to 112 ) & $5(4$ to 6$)$ \\
\hline Full remission & $45 \%$ & $22 \%$ & $107 \%$ (57 to 172$)$ & $5(4$ to 7$)$ \\
\hline Adverse events & $\begin{array}{l}\text { TCA } \\
81 \% \\
\text { Weigh }\end{array}$ & $\begin{array}{l}\text { Placebo } \\
59 \% \\
\text { vent rates }\end{array}$ & $\begin{array}{l}\text { RRI }(95 \% C I) \\
37 \%(15 \text { to } 67)\end{array}$ & $\begin{array}{l}N N H(C I) \\
5(3 \text { to } 10)\end{array}$ \\
\hline $\begin{array}{l}\text { Treatment response } \\
\text { Full remission }\end{array}$ & $\begin{array}{l}S S R I \\
61 \% \\
48 \% \\
\text { Weigh }\end{array}$ & $\begin{array}{l}\text { Placebo } \\
39 \% \\
27 \% \\
\text { vent rates }\end{array}$ & $\begin{array}{l}R B I(95 \% \text { CI }) \\
56 \%(33 \text { to } 82) \\
78 \%(35 \text { to } 135)\end{array}$ & $\begin{array}{l}N N T(C I) \\
5(4 \text { to } 7) \\
5(4 \text { to } 9)\end{array}$ \\
\hline $\begin{array}{l}\text { Treatment response } \\
\text { Full remission }\end{array}$ & $\begin{array}{l}\text { MAOI } \\
55 \% \\
50 \%\end{array}$ & $\begin{array}{l}\text { Placebo } \\
22 \% \\
14 \%\end{array}$ & $\begin{array}{l}R B I(95 \% C I) \\
158 \%(83 \text { to } 264) \\
271 \%(125 \text { to } 530)\end{array}$ & $\begin{array}{l}N N T(C I) \\
3(2 \text { to } 5) \\
3(2 \text { to } 4)\end{array}$ \\
\hline
\end{tabular}

*TCA = Tricyclic antidepressant; SSRI $=$ Selective serotonin reuptake inhibitor; MAOI = Monoamine oxidase inhibitor. Other abbreviations defined in glossary; RBI, RRI, NNT, NNH, and CI calculated from data in article.

Sources of funding: CAPES (Ministry of Education), Brazil and Institute of Psychiatry, UK

For correspondence:Dr M S de Lima, Department of Mental Health, Universidade Federal de Pelotas, Avenida Duque de Caxias, 250, Pelotas, Rio Grande do Sul, 96100, Brazil. Fax +55 532712645.

\section{Commentary}

Since the diagnosis of dysthymia was first recognised in 1980, there has been controversy surrounding its proper treatment. Evidence of the efficacy of pharmacotherapy has emerged slowly, and progress has been hindered by the decision of most countries' regulatory agencies not to require studies of dysthymia as part of the registration process for new antidepressants. Furthermore, many studies "lump" patients with dysthymia together with patients with other chronic depressive disorders (ie, "double" depression and chronic major depression) - an approach that fails to address the more pragmatic question: is dysthymia responsive to antidepressant medications? The metaanalysis by Lima and Moncrieff answers this question definitively. There is now an adequate number of double blind, placebo controlled studies to document that diverse classes of antidepressants are effec- tive treatments of dysthymia. Such effectiveness across classes of medication also suggests that if one antidepressant is ineffective, a second trial with a different type of medication may still be helpful. These findings have 3 important implications. Firstly, demonstration of effective treatments carries with it the obligation to apply and extend these findings broadly to clinical settings, including both psychiatric and general medical practices. All available evidence suggests that the vast majority of patients with dysthymia do not receive treatment with antidepressants. ${ }^{1}$ Secondly, and perhaps surprisingly, the placebo response rates in the studies reviewed by Lima and Moncrieff are high. Thus, a subset of patients with chronic depression benefit from non-specific therapeutic support. Although placebo therapy is not an ethical option for practitioners, supportive counselling and more formal psychotherapies are acceptable options. The relative merits of psychotherapeutic and pharmacological treatments now need to be studied in patients with dysthymia. Finally, the full benefits of antidepressants are gauged over months of treatment, not a few weeks. It is likely that many patients with dysthymia will warrant indefinite, preventative pharmacotherapy. However, no such studies have yet been done. The data reviewed by Lima and Moncrieff thus provide the foundation for a new generation of research on the treatment of a common, albeit mild, form of chronic depression.

Michael E Thase, MD

University of Pittsburgh School of Medicine Pittsburgh, Pennsylvania, USA

1 Hirschfeld RM, Keller MB, Panico S, et al.JAMA 1997;227:333-40. 